\title{
Effect of fortification of pasta with natural immune booster Moringa oleifera leaf powder (MLP) on cooking quality and sensory analysis.
}

\section{Efecto de la fortificación de la pasta con refuerzo inmunológico natural en polvo de hojas de Moringa oleifera (MLP) sobre la calidad de cocción y el análisis sensorial}

\author{
Namrata ${ }^{1 *}$ and Shiv Kumar $^{1}$ \\ 1 Institute of Food Technology, Bundelkhand University, Jhansi - 284128, Uttar Pradesh, \\ India \\ *Corresponding author: namrata2002@gmail.com; Tel. phone: +91 9451122575
}

\begin{abstract}
Malnutrition is a worldwide escalating severe problem, impacting majority of the Indian population. Currently, it is difficult to meet, the nutritional requirements with a limited type of stored food as compared to the variety of freshly available food. In such a scenario incorporating, the immune-boosting nutritional ingredients in a commonly consumed food can be adopted as one of the nutritional approaches. Hence, as an alternate to fresh food, the usage of a fortified high-nutrient food products can be one of the approaches e.g., the inclusion of fortified pasta in meals. Moringa oleifera is a fastgrowing underutilized tree with high nutritional value. Its leaves are rich sources of bioactive components, vitamin A, vitamin $\mathrm{C}$ and Iron. Fortification of pasta products with Moringa oleifera leaf powder can be one of the cost-effective approaches and, a best immunity booster supplement for enhancing the nutritional value of pasta-based products which can be stored for several months. In current study, the preparation of pasta fortified with varying concentrations of Moringa oleifera leaf powder (MLP) was attempted, followed by its cooking quality analysis (cooking time, cooking weight, cooking loss and water absorption) and sensory attributes evaluation (based on 9 points hedonic scale including the colour, taste, texture, flavour and overall acceptability). The results from the qualitative as well as quantitative analysis suggest that the fortification of pasta with Moringa oleifera leaves differentially modified the sensory characteristics of the pasta in a concentration-dependent manner. The present study indicates that the fortification of
\end{abstract}


Sustainability, Agri, Food and Environmental Research, (ISSN: 0719-3726), 9(3), 2021; 408-424 http://dx.doi.org/10.7770/safer-V0N0-art2303

pasta with Moringa oleifera leaf powder can act as a natural immune booster, and has the potential to reduce the probability of microbial infections.

Keywords: Bioactive Components, Fortification, Moringa oleifera, Pasta.

\section{RESUMEN}

La desnutrición es un problema grave que se agrava en todo el mundo y que afecta a la mayoría de la población india. Actualmente, es difícil satisfacer los requisitos nutricionales con tipos limitados de alimentos almacenados en comparación con una variedad de alimentos recién disponibles. En tal escenario, la incorporación de los ingredientes nutricionales que estimulan el sistema inmunológico en un alimento de consumo común se puede adoptar como uno de los enfoques nutricionales. Por lo tanto, como alternativa a los alimentos frescos, el uso de alimentos enriquecidos con alto contenido de nutrientes puede ser uno de los enfoques, p. inclusión de pasta enriquecida en las comidas. Moringa oleifera es un árbol subutilizado de rápido crecimiento con un alto valor nutricional y sus hojas son fuentes ricas en componentes bioactivos, vitamina $A, C$ y hierro. La fortificación de la pasta con polvo de hojas de Moringa oleifera puede ser uno de los enfoques rentables y el mejor suplemento de refuerzo de la inmunidad para mejorar el valor nutricional de los productos a base de pasta y, también, que se puede almacenar durante varios meses. En el estudio actual, se intentó la preparación de pasta fortificada con una cantidad variable de polvo de hojas de Moringa oleifera (MLP), seguida de un análisis de calidad de cocción (tiempo de cocción, peso de cocción, pérdida de cocción y absorción de agua) y evaluación de atributos sensoriales basada en 9 puntos hedónicos escala (incluido el color, el sabor, la textura, el sabor y la aceptabilidad general). Los resultados del análisis tanto cualitativo como cuantitativo sugieren que la fortificación de la pasta con Moringa oleifera modificó diferencialmente las características sensoriales de la pasta de una manera dependiente de la concentración. Concluimos que la fortificación de la pasta con Moringa oleifera puede actuar como un refuerzo inmunológico natural y tiene el potencial de reducir la probabilidad de infecciones microbianas.

Palabras clave: Componentes bioactivos, Fortificación, Moringa oleifera, Pasta.

\section{INTRODUCTION}

Malnutrition is an escalating problem in many countries including India, especially among the children and women from rural area. It may lead, to a lower immunity which results in an easy target for many diseases. People with lower immunity are at higher risk of catching infection, while people with strong immunity are at lower risk. Nutritionally rich diet helps in maintaining the strong immunity and, the natural products which provide nutrition and dietary fibre, may work as an immune booster. 
Pasta is popular among all over the world due to its ease in cooking and availability in many varieties. It was one of the first foods for which the USFDA permitted nutritional improvement (Marconi and Carcea, 2001). FDA permitted fortification of pasta with vitamins and iron enrichment in 1949's (FDA, 1999). Processed and staple foods like pasta products is known as one of the most nutritive and gastronomic dish with ease of preparation, sensory appeal, long storage capability and cost effectiveness (Antogenelli, 1980; Martinez, et al., 2007). It is cholesterol free energy source for human body which is rich in starch, carbohydrate, thiamine, iron, riboflavin and niacin, while low in calorie, proteins (deficient in lysine), fats and dietary fibres (Feillet and Dexter, 1996; Savita, et al., 2013). Its production was reported to be approximately 14 million tons in 2014 (IPO, 2018). In-spite of these, the pasta products are still not considered as a healthy food due to low nutrients and dietary fibre content (Mishra and Bhatt, 2016). Hence, the fortification of pasta with natural nutritional components could be a better option and in day to day requirement and such food can also be stored for a longer time.

Pasta is mainly produced by extruders, which operate on the auger extrusion principle in which kneading and extrusion are performed in a single operation. Due to the nutritional advantages along with the appeal of pasta amongst consumers, its fortification is a better option to make pasta products, a potential vehicle for nutraceuticals such as vitamins (Verardo, et al., 2009) and minerals. Pasta quality depends on selection of raw material, and it is mainly made from durum wheat, semolina flour, and water. Sometimes production of pasta by mixing eggs and salts, and drying also play a crucial role (Dexter and Matsou, 1979; Toepfer, et al., 1972; Kill, et al., 2001a). Its quality is characterized by various parameters viz., appearance, texture (firmness, strength, elasticity, less stickiness), flavour, minimum cooking loss, water absorption and swelling index after cooking (Dexter and Matsou, 1979; Cubadda, 1994; Sissons, et al., 2008). Many functional foods are derived from plants that naturally contain bioactive elements with specific health benefits to human and can often prevention from certain diseases (Abd El-Baky and ElBaroty, 2013; Stephen, et al., 2009), and interactions with macronutrients, including proteins, lipids, and carbohydrates provide critical structural and potentially nutritional attributes to pasta products (Bordenave, et al., 2014).

Moringa oleifera (family name: Moringaceae, common name: Drumstick, sahjan and munga, miracle tree), is a fast growing highly nutritional underutilized tree of a tropical and subtropical region of India, and an effective solution to fight malnutrition. Moringa oleifera is an easily cultivable tree which makes it, a sustainable remedy for malnutrition. Almost, all parts of this plant is used for taste \& flavor or as vegetable and seed activities for its nutritional value, and purported medicinal properties i.e. anti-inflammatory, anticancer, anti-diabetic (Kakde, et al., 2018). Many countries treat children and women by 
Sustainability, Agri, Food and Environmental Research, (ISSN: 0719-3726), 9(3), 2021; 408-424 http://dx.doi.org/10.7770/safer-V0NO-art2303

adding Moringa oleifera in their diet to combat malnutrition (Kasolo, et al., 2010). Moringa oleifera leaves are most nutritious part of the plant. They are rich source of micro \& macro nutrients as well as bioactive elements viz., antioxidants, phytochemicals, vitamin $B$, vitamin $C$, vitamin $D$, vitamin $E$, pro-vitamin A (as beta-carotene), xanthans, proteins and minerals like iron, calcium, potassium, zinc, magnesium with low calorific value (Lakshmipriya, et al., 2016).

Moringa oleifera appears to have the nutritional potential and, the incorporation or fortification in staple foods is a cost effective solution which may help in tackling the human community affected by the nutrient deficiencies and malnutrition especially, the woman and children from rural area (Owusu, et al., 2011; Aluko, et al., 2013) and also in boosting immunity. The current study was carried out to explore the possible functionality of fortification of pasta with varying concentrations of Moringa oleifera leaf powder (MLP) followed by evaluation of the cooking quality (including the cooking time, cooking weight, cooking loss/gruel loss and water absorption) and sensory attributes evaluation (taste, texture, flavour, colour and overall acceptability on the basis of 9-point hedonic scale).

\section{MATERIALS AND METHODS}

The current study was carried out to evaluate the cooking and sensory quality of pasta, fortified with varying concentrations of Moringa oleifera leaf powder (MLP). This study was carried out at the Institute of Food Technology, Bundelkhand University, Jhansi, India. The details of materials and methodology are described under the following sections:

I. Selection and procurement of raw materials: Raw materials used in current study were, the refined wheat flour, semolina and Moringa leaves powder (MLP). The fresh and healthy leaves were collected from Moringa oleifera tree from Experimental farm, Indian Grassland and fodder research Institute (IGFRI), ICAR, Jhansi. Good quality commercially available refined wheat flour, semolina and other ingredients were purchased from local market of Jhansi.

II. Preparation of Moringa oleifera leaf powder: To prepare the Moringa oleifera leaf powder (MLP), initially, the fresh and healthy leaves from the Moringa oleifera tree were manually selected and collected carefully, while damaged leaves were discarded as well. All the leaves were washed gently in tap water for the removal of all kind of dirt and dust. Removal of excess amount of water was carried out by spreading the leaves on a perforated tray for 10-15 min. Subsequently, the blanching of the leaves was carried out by boiling the leaves for 3-4 min in clean water followed by cooling of leaves in cold water 
Sustainability, Agri, Food and Environmental Research, (ISSN: 0719-3726), 9(3), 2021; 408-424 http://dx.doi.org/10.7770/safer-V0N0-art2303

for sufficient time. Leaves were further dried in a cabinet drier at around $55^{\circ} \mathrm{C}$ for $1.5-$ 3.0 $\mathrm{hr}$ followed by cooling at room temperature for 10-15 min. MLP fortification can also be carried out using un-blanched leaves as well. After drying, leaves were ground into a fine powder using mixer-grinder and separated using small pore size stainless steel sieve. Immediate to this, the powder was quickly stored in an airtight polythene packaging bag/container to avoid absorption of the surrounding moisture during or after grinding which may degrade its quality and nutrient content (Srivastava and Kumar, 2009). The powder can be stored for around 4-6 months under the controlled conditions in air-tight containers which are protected from direct sunlight and humidity.

III. Development of standard (control) and fortified pasta blends with Moringa oleifera leaf powder: The pasta was prepared by using refined wheat flour, semolina with various concentrations of Moringa oleifera leaf powder (MLP) and required amount of water. The composition and properties of raw materials used for pasta preparation directly affect the physio-chemical properties of the final product (Nilusha, et al., 2019). Preparation of control samples (it contains only refined wheat flour, semolina and water) and fortified pasta blends (with varying concentration of MLP e.g. $5 \mathrm{~g}, 10 \mathrm{~g}$ and $15 \mathrm{~g}$ ) included the; dough making by mixing, kneading, extruding and drying. The process started with the mixing of refined wheat flour, semolina and water in pasta mixer-extruder machine (Model: Dolly La Monferrina, Italy) followed by kneading into dough which include many chemical, physical and biochemical process (Fennema, 1996, Andersen, 1993). Subsequently, dough was passed through a single screw extruder fitted with an adjustable die. The control and fortified pasta samples were dried in a cabinet drier for $1.15-1.30$ $\mathrm{hr}$ at around $55^{\circ} \mathrm{C}$ followed by cooling at ambient room temperature for $10-15 \mathrm{~min}$. (Figure 1). The dried pasta samples were packed in air-tight polythene bags and stored in a cool and dry place for further analysis.

IV. Cooking quality analysis: Cooking quality is one of the major qualitative parameters of pasta evaluation for its acceptance. Cooking quality of control and fortified pasta was carried out by using various parameters viz., the optimum cooking time (OCT), cooked weight, cooking loss (solid gruel loss), and water absorption. The methodology and applied mathematical formulas used in the calculation of these parameters are:

a. Optimum cooking time: The optimum cooking time for control and fortified pasta blends was determined according to the AACC method 66-50 (AACC 2008). Optimal cooking time (OCT) of pasta samples depends primarily on the rate of water penetration and starch gelatinisation (Edwards, et al., 1993). 


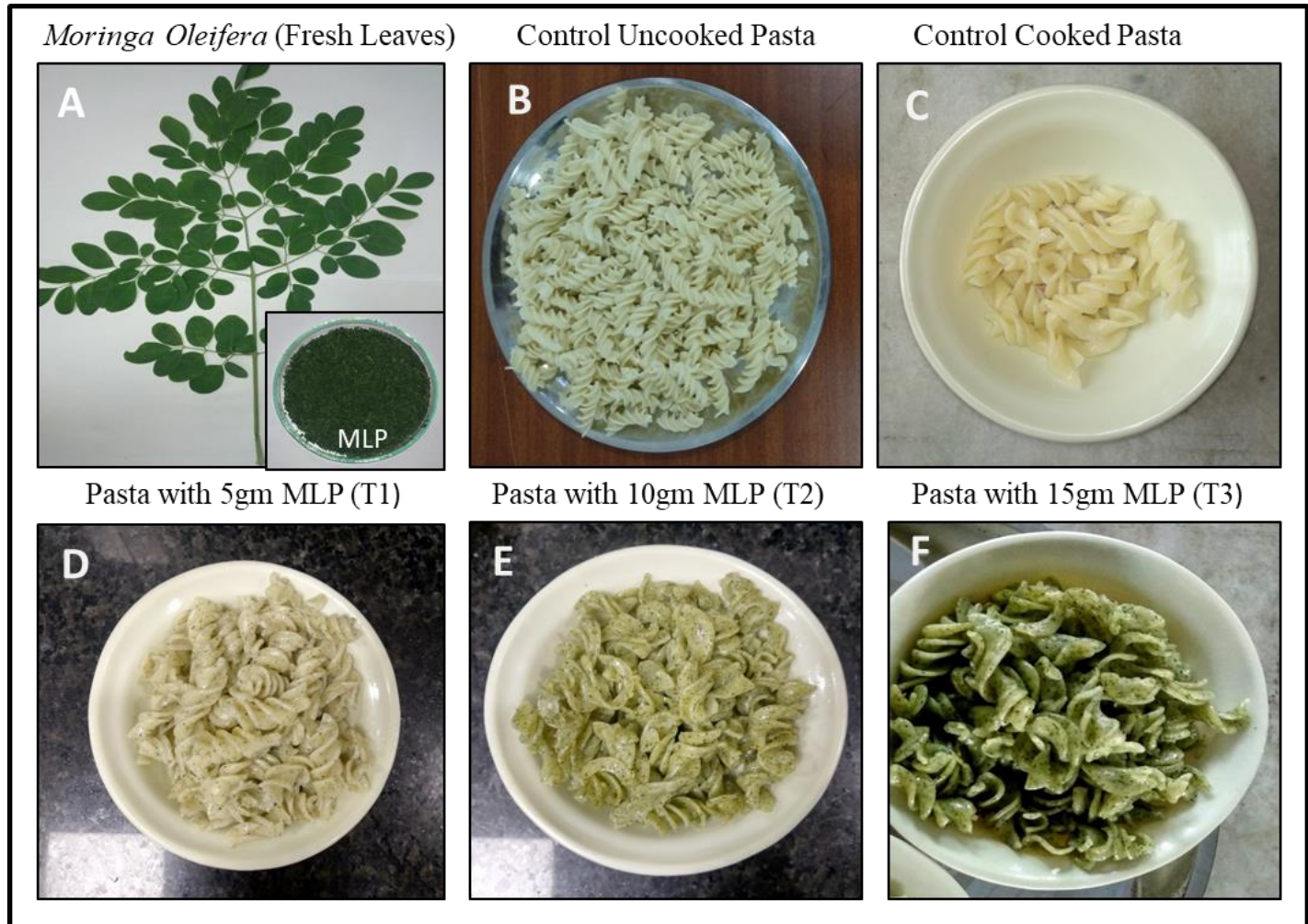

Figure.1: Images showing the fresh selected leaves of Moringa oleifera and MLPMoringa oleifera leaves powder (A), and Control Uncooked Pasta (B), Control Cooked Pasta (C), Cooked samples of Pasta blends Fortified with Moringa oleifera leaves powder (MLP) at various concentrations (D-F).

$10 \mathrm{~g}$ each of the pasta samples was taken for cooking in $100 \mathrm{ml}$ of boiling water. Samples were analysed for optimum cooking time by squeezing a strands of cooked pasta samples between two transparent glass slides in some time intervals until the disappearance of the white centre core of the pasta strand occur which is considered as optimum cooking time (Delcour, et al., 2000, Edwards, et al., 1993, Tudorica, et al., 1993, Brennan, et al., 2004).

\section{b. Cooking Loss/ Solid Gruel Loss (CL/SGL): Cooked the samples, as per standard} procedure, AACC method 16-50 (AACC, 2000). In this method, the $10 \mathrm{gm}$ of each sample was cooked in a vessel containing $300 \mathrm{ml}$ of boiling water for an optimum cooking time. Subsequently, the cooking water was drained into a glass beaker and $25 \mathrm{ml}$ of this cooking water was taken out in pre-weighed glass petri dish followed by evaporation in hot air oven at $105^{\circ} \mathrm{C}$ till dryness. The petri dish was weighed again with the dried solids. Finally, the solid loss is calculated and expressed as cooking loss (Gull, et al., 2015). In current study, the cooking loss carried out by cooking the control and blends pasta samples for $10 \mathrm{~min}$ to assess the effect of cooking time on the Cooking loss/ Solid Gruel Loss. Cooking 
Sustainability, Agri, Food and Environmental Research, (ISSN: 0719-3726), 9(3), 2021; 408-424 http://dx.doi.org/10.7770/safer-V0N0-art2303

loss (Edwards, et al., 1993; Brennan, et al., 2004; Bui and Small, 2007) was calculated by using following formula:

Cooking Loss $=\frac{\text { Weight of cooking water dried residue }}{\text { Weight of raw pasta }} \times 100$

c. Cooking weight: $10 \mathrm{gm}$ of each control and fortified pasta samples was cooked in $100 \mathrm{ml}$ of water for an optimum time, and cooking weight was determined by draining the cooked pasta with the help of stainless steel sieves and then weighing this drained pasta (Ronge, et al., 2017).

d. Water absorption: The water absorption was calculated by weighing the drained cooked pasta. Water absorption (Edwards, et al., 1993; Bui and Small, 2007; Fellows, et al., 1997) was calculated by using following formula:

$$
\text { Water Absorption }=\frac{\text { Weight of cooked pasta }- \text { Weight of raw pasta }}{\text { Weight of raw pasta }} \times 100
$$

$V$. Sensory analysis: Sensory attributes analysis was carried out to assess the effects of incorporation of MLP in pasta by a panel of semi-trained members from the Institute of Food Technology, B.U., Jhansi. The pasta samples were cooked for the optimal cooking time for scaling these sensory attributes. This analysis was carried out by calculating 9 Point Hedonic scale Score System i.e., Colour, Texture, Taste, Flavour and Overall acceptability (OAA) (Ranganna, 1986) of the freshly cooked control and MLP fortified pasta samples. These samples were served in a random order to evaluate all the sensory attributes for each samples from 9-1 point scale, ranging from 'like extremely' to 'dislike extremely' respectively. This scale helps to find out the best pasta sample in between among the control and fortified MLP pasta blends (Taneya, et al., 2014).

Statistical Analysis: Three independent observations of each sample for each test were taken and mean of these observations was used for statistical analysis i.e., the calculation of SD and $p$-value. The data obtained were subjected to analysis of variance (ANOVA) using complete randomized design.

\section{RESULTS AND DISCUSSION}

In current study, the cooking and sensory quality evaluation of pasta, fortified with varying concentrations of Moringa oleifera leaf powder was attempted. The pasta samples 
i.e., the control and MLP incorporated pasta blends were evaluated for cooking quality and sensory analysis on a hedonic score on 9-1 point scale. This evaluation was performed for arriving at the best combination for the fortification of pasta with Moringa oleifera leaf powder (MLP). The results obtained from the qualitative as well as quantitative analysis of these pasta samples are presented in the following sections:

A. Cooking quality: Cooking quality is an important parameter for assessing the quality of pasta for its final acceptance. Cooking quality of pasta samples from freshly cooked control and MLP fortified pasta blends were assessed using various parameters viz., the optimum cooking time, cooking weight, cooking loss (solid gruel loss) and water absorption. Cooking properties were assessed after completion of cooking the samples. The results from control and fortified pasta samples are presented in Figure 2-6, Table-1 and also discussed in detail in each section as follows;

i. Optimum cooking time: It was observed that the optimal cooking time depends, primarily on the rate of water penetration and starch gelatinisation (Edward, 1993). To assess the optimum cooking time, the control and pasta fortified with MLP samples were cooked completely and, the optimum cooking time (OCT) was calculated by intermittently observing the time of disappearance of the core of pasta during cooking by squeezing it between the two transparent glass slides. Observations indicated that the OCT ranges from $7.0 \mathrm{~min}$ to $9.46 \mathrm{~min}$ for the control pasta and fortified pasta with varying concentration of MLP i.e. $5 \mathrm{gm}, 10 \mathrm{gm}$ and $15 \mathrm{gm}$ in T1, T2 and T3 treatment groups respectively (Figure 2 ) however, the OCT may vary substantially, depending on the method of cooking adopted. OCT was increased in a concentration dependent manner e.g. the OCT increased with the increasing concentrations of MLP. The OCT was $7 \mathrm{~min}$ for the control pasta and was 8,9 and 9.46 min for MLP fortified pasta samples (5, 10 and 15gm) respectively. It indicates that the fortified pasta samples took a little longer time for optimum/or complete cooking as compared to the control sample. The relative difference in OCT time with the varying concentrations of MLP can be attributed to the enhanced reconstitution of MLP powder with pasta matrix at lower concentrations of MLP compared to the higher concentrations.

ii. Cooking weight: Control and fortified pasta samples were cooked completely followed by cooked weight analysis. Cooked weight was determined by taking the weight of pasta drained with the help of stainless steel sieve. The cooking weight of control pasta and various treatments groups i.e., the T1, T2 and T3 were determined, and the results obtained are presented in Figure 3. The cooking weight in control pasta sample was $45.5 \mathrm{gm}$, where as in MLP fortified pasta, it was $51.91 \mathrm{gm}, 55.66 \mathrm{gm}$ and $58.50 \mathrm{gm}$ in $\mathrm{T} 1(5 \mathrm{gm}), \mathrm{T} 2(10 \mathrm{gm})$ and T3 $(15 \mathrm{gm})$ treatment groups respectively (Figure 3$)$. These 
observations indicated that the weight of cooked pasta was progressively increased with the increasing concentration of Moringa oleifera leaf powder (MLP).

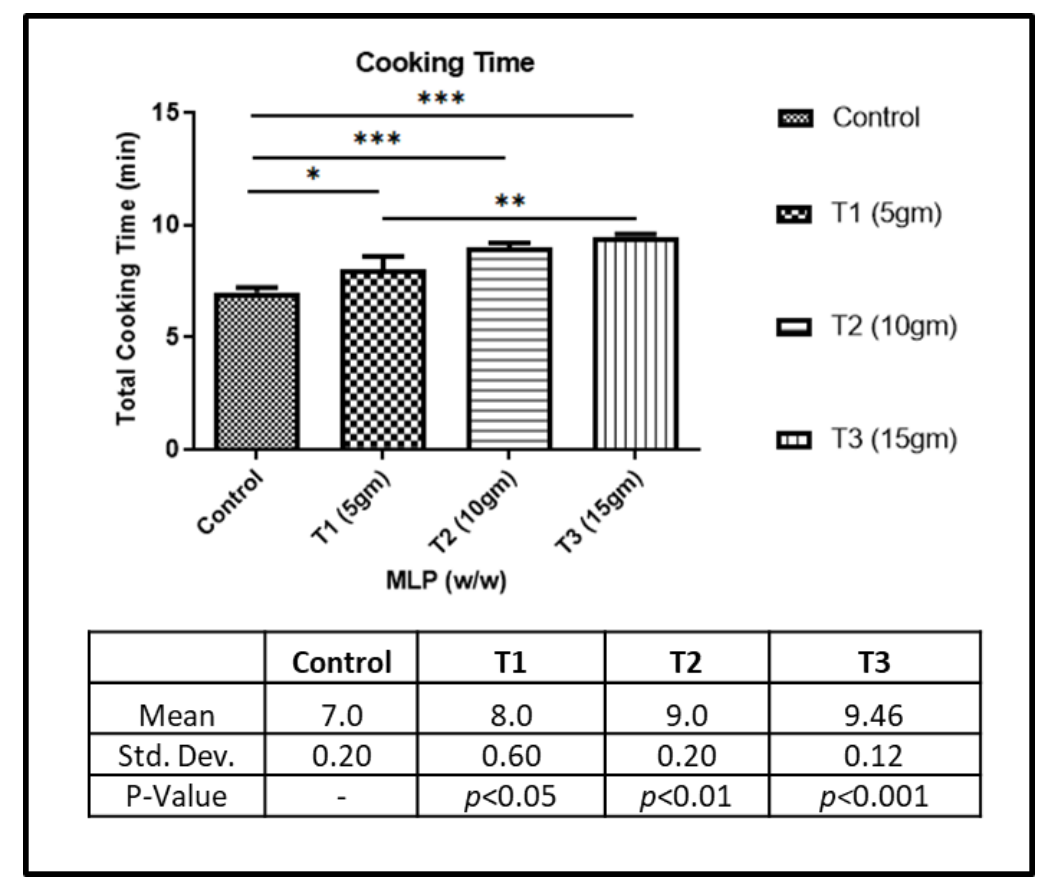

Figure 2: Cooking time (in min) of Control and Pasta fortified with MLP at various concentrations i.e. T1 $(5 \mathrm{gm})$, T2 $(10 \mathrm{gm})$, T3 $(15 \mathrm{gm})$. Values are Mean ( $\pm 1 \mathrm{SD})$ of three observations from independent experiments. Significance of difference is calculated among Control Vs. Treatments Groups (T1, T2, and T3) and between treatments i.e. T1-T3. $(* p<0.05, * * p<0.01, * * * p<0.001)$

iii. Water absorption: Water absorption of cooked pasta samples were determined using well established method. The observations indicated that water absorption increased with the increasing concentration of MLP. The water absorption ranges from $130.6 \%-162.2 \%$ including control pasta samples and it was found maximum i.e. $162.2 \%$ in pasta fortified with 15gm of MLP (T5), whereas the minimum water absorption was observed in pasta fortified with $5 \mathrm{gm}$ of MLP (T1) i.e. $157.7 \%$. The control pasta was found to have minimum water absorption i.e. $130.6 \%$ as compared to all other treatment groups. The detailed results are shown in Figure 4. The relative differences in water absorption were not significantly different among all the treatment groups which can be attributed to the water absorbing properties of MLP probably due to fibre content (Foschia, 2015). 


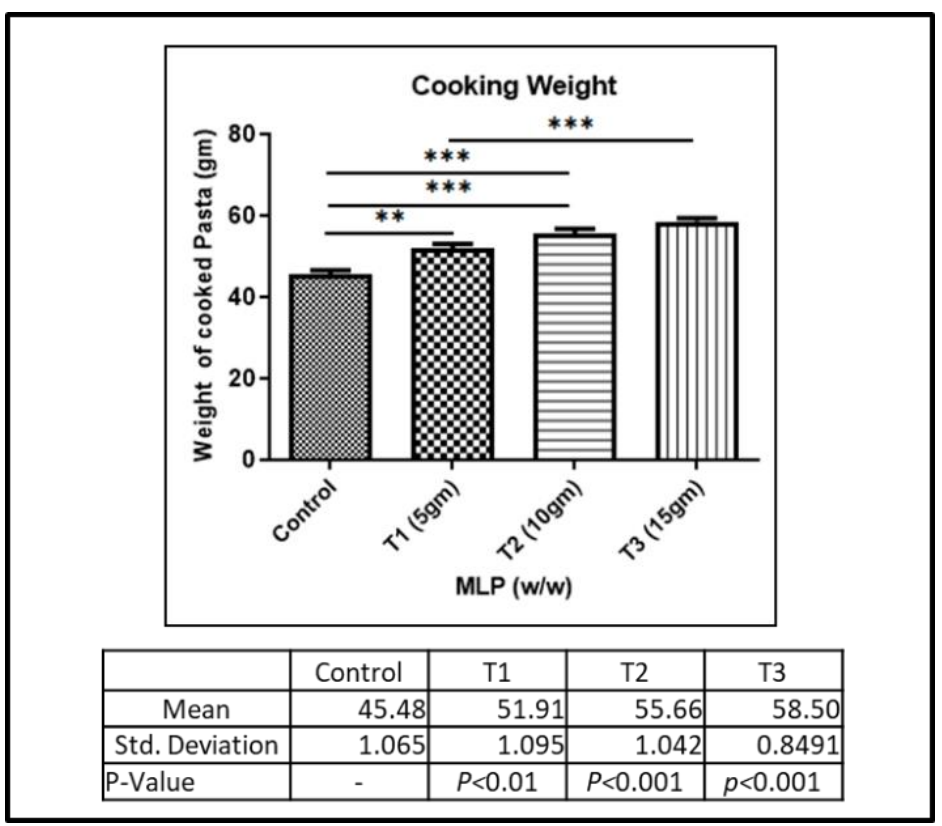

Figure. 3: Cooking Weight of Control and Pasta fortified with MLP at various concentration i.e. T1 $(5 \mathrm{gm})$, T2 $(10 \mathrm{gm})$, T3 $(15 \mathrm{gm})$. Values are Mean $( \pm 1 \mathrm{SD})$ of three observations from independent experiments. Significance of difference is calculated among Control Vs. Treatments Groups (T1, T2, and T3) and between treatments i.e. T1-T3. $(* p<0.05, * * p<0.01, * * * p<0.001)$

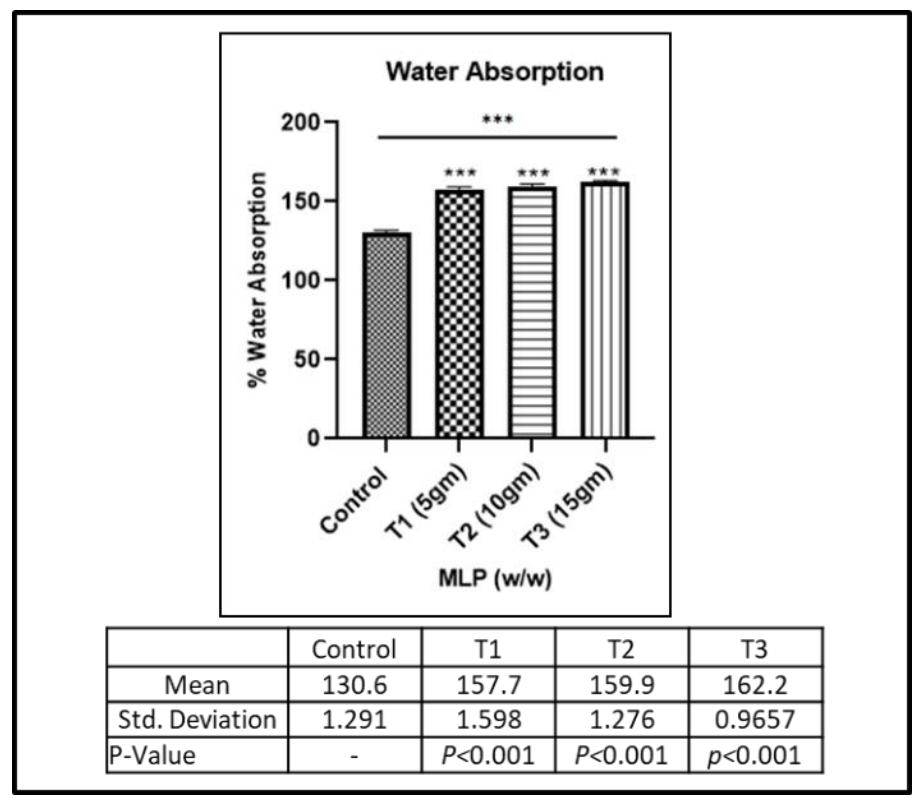

Figure. 4: Water Absorption of Control and Pasta fortified with MLP at various concentration i.e. T1 $(5 \mathrm{gm}), \mathrm{T} 2(10 \mathrm{gm}), \mathrm{T} 3(15 \mathrm{gm})$. Values are Mean $( \pm 1 \mathrm{SD})$ of three observations from independent experiments. Significance of difference is calculated among Control Vs. Treatments Groups (T1, T2, and T3) and between treatments i.e. T1-T3. $(* p<0.05, * * p<0.01, * * * p<0.001)$

iv. Cooking Loss/ Solid Gruel Loss: Cooking loss is one of the important parameters in assessing the cooking quality of pasta. The amount of total content of solids which is leached out in the cooking water during cooking of the pasta is considered as the gruel 
loss. The gruel loss is also considered as the cooking loss $(C L)$ therefore, the gruel in the cooking water is commonly used as an indicator of pasta quality. It represents the resistance of pasta to disintegrate during the boiling, thus the low amount of solids into the cooking water indicates good cooking quality (Pagani, et al. 2007). In the current study, the gruel loss was calculated in control and in different combinations of pasta fortified with MLP. The observations indicated that the cooking loss/ solid gruel loss increased with the increasing concentration of MLP i.e. $5.0-15.0 \mathrm{gm}$ as well as with cooking time compared to control pasta. The gruel loss ranged from $1.25 \mathrm{gm}$ to $1.68 \mathrm{gm}$ in MLP fortified pasta samples as compared to control i.e. $1.03 \mathrm{gm}$ with $10 \mathrm{~min}$ cooking (Figure 5). In the treatment groups, the maximum gruel loss was observed at $10 \mathrm{~min}$, in treatment T3 $(15 \mathrm{gm})$ followed by treatment T2 $(10 \mathrm{gm})$ and minimum solid gruel loss was observed in T1 (5gm), However, the least gruel loss was found in control sample. The solid gruel loss was significantly different among all the treatment groups. This cooking loss during preparation of fortified pasta with MLP may also cause the nutrient loss which may be due to the solubility of MLP in water, cooking temperature and time. Therefore, to prevent the nutritive loss at higher treatment concentrations i.e. $15 \mathrm{gm}$ MLP (T3), it is much needed to optimize the cooking condition of MLP fortified pasta and the use of proper binder/ stabilizer as well.

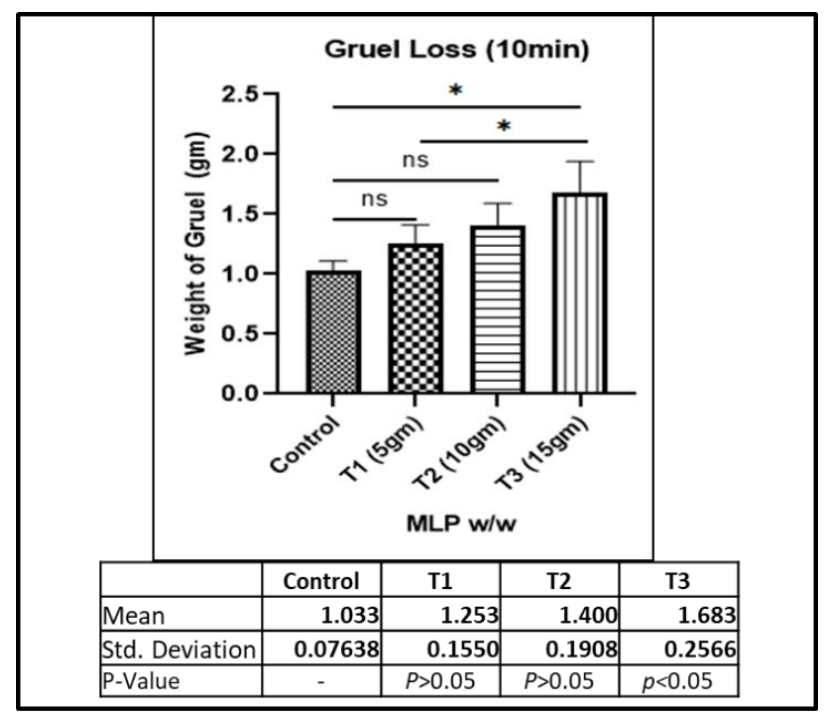

Figure. 5: Solid Gruel Loss / Cooking Loss (in gm) of Control and Pasta fortified with MLP at various concentration i.e. T1 $(5 \mathrm{gm}), \mathrm{T} 2(10 \mathrm{gm}), \mathrm{T} 3(15 \mathrm{gm})$. Values are Mean ( $\pm 1 \mathrm{SD}$ ) of three observations from independent experiments. Significance of difference is calculated among Control Vs. Treatments Groups (T1, T2, and T3) and between treatments i.e. T1-T3. $(* p<0.05, * * p<0.01, * * * p<0.001)$

b. Sensory evaluation: Sensory evaluation of pasta is an important factor for its acceptability analysis on the basis of sensorial performance as well as for future promotion/ commercialisation. All the sensory parameters for all samples, scored positively $(>3)$ i.e. 
7.4 to 8.57 score, revealing a good acceptance of fortified pasta by the panellists (Figure 6 ). It is one of the most important parameters for assessing the quality of pasta products which allows us to evaluate the overall attributes of cooked pasta. This is also an important parameter for predicting the future commercialisation of pasta products. In current study, the sensory analysis of freshly cooked fortified pasta with Moringa oleifera leaf powder (MLP) was carried out using 9-point hedonic scale with the help of a panel of the semitrained evaluator from the Institute of Food Technology where this study was carried out. The control and fortified pasta samples with MLP i.e. 5-15gm were evaluated for the sensory parameters like colour, flavour, texture, taste and overall acceptability (OAA). The effect of fortification of pasta with MLP on sensory parameters is shown in Figure 6. The OAA score of pasta fortified with moringa leaves varied from 7.9 to 8.8. The hedonic scale score appears to increase in a concentration dependent manner in all the parameters except the flavour and texture. Freshly cooked pasta fortified with $15 \mathrm{gm}$ of moringa (T3) scored maximum in all the parameters like colour, flavour and OAA except the texture. The pasta fortified with $10 \mathrm{gm}$ of MLP found to have a relatively less score in flavour and texture as compared to T1 $(5 \mathrm{gm})$ and T3 $(15 \mathrm{gm})$ MLP. Taken together, these observations suggest that the pasta fortification with $15 \mathrm{gm}$ of moringa (T3) resulted in the most acceptable combination though it has relatively lesser score in texture which can be attributed to no significant role of MLP in enhancing the texture. The colour, texture and taste attributes were not significantly different as compared to flavour in pasta sample fortified with $15 \mathrm{gm}$ of MLP (T3).

Table 1: Summary of Cooking Quality and Sensory over all acceptability (OAA) of Control and Pasta fortified with MLP at various concentration i.e. T1 (5gm), T2 (10gm), T3 $(15 \mathrm{gm})$. Values are Mean ( $\pm 1 \mathrm{SD}$ ) of three observations from independent experiments.

\begin{tabular}{|c|c|c|c|c|c|c|}
\hline \multirow[t]{2}{*}{ Groups } & \multirow{2}{*}{$\begin{array}{l}\text { MLP } \\
(w / w)\end{array}$} & \multicolumn{5}{|c|}{ Summary of Cooking Quality and Sensory OAA } \\
\hline & & $\begin{array}{l}\text { Cooking } \\
\text { Time } \\
\text { (min) }\end{array}$ & $\begin{array}{l}\text { Cooking } \\
\text { Weight }\end{array}$ & $\begin{array}{c}\text { Water } \\
\text { Absorption }\end{array}$ & $\begin{array}{c}\text { Cooking loss } \\
\text { (Solid Gruel } \\
\text { Loss) }\end{array}$ & $\begin{array}{c}\text { Sensory } \\
\text { OAA }\end{array}$ \\
\hline Control & Ogm & $7 \pm 0.2$ & $45.47 \pm 1.06$ & $130.6 \pm 1.29$ & $1.033 \pm 0.076$ & 7.5 \\
\hline $\mathrm{T} 1$ & $5 \mathrm{gm}$ & $8 \pm 0.6$ & $51.91 \pm 1.09$ & $157.7 \pm 1.59$ & $1.25 \pm 0.15$ & 7.9 \\
\hline $\mathrm{T} 2$ & $10 \mathrm{gm}$ & $9 \pm 0.2$ & $55.66 \pm 1.04$ & $159.9 \pm 1.27$ & $1.4 \pm 0.18$ & 8.3 \\
\hline T3 & $15 \mathrm{gm}$ & $9.46 \pm 0.12$ & $58.49 \pm 0.86$ & $162.2 \pm 0.966$ & $1.683 \pm 0.25$ & 8.8 \\
\hline
\end{tabular}




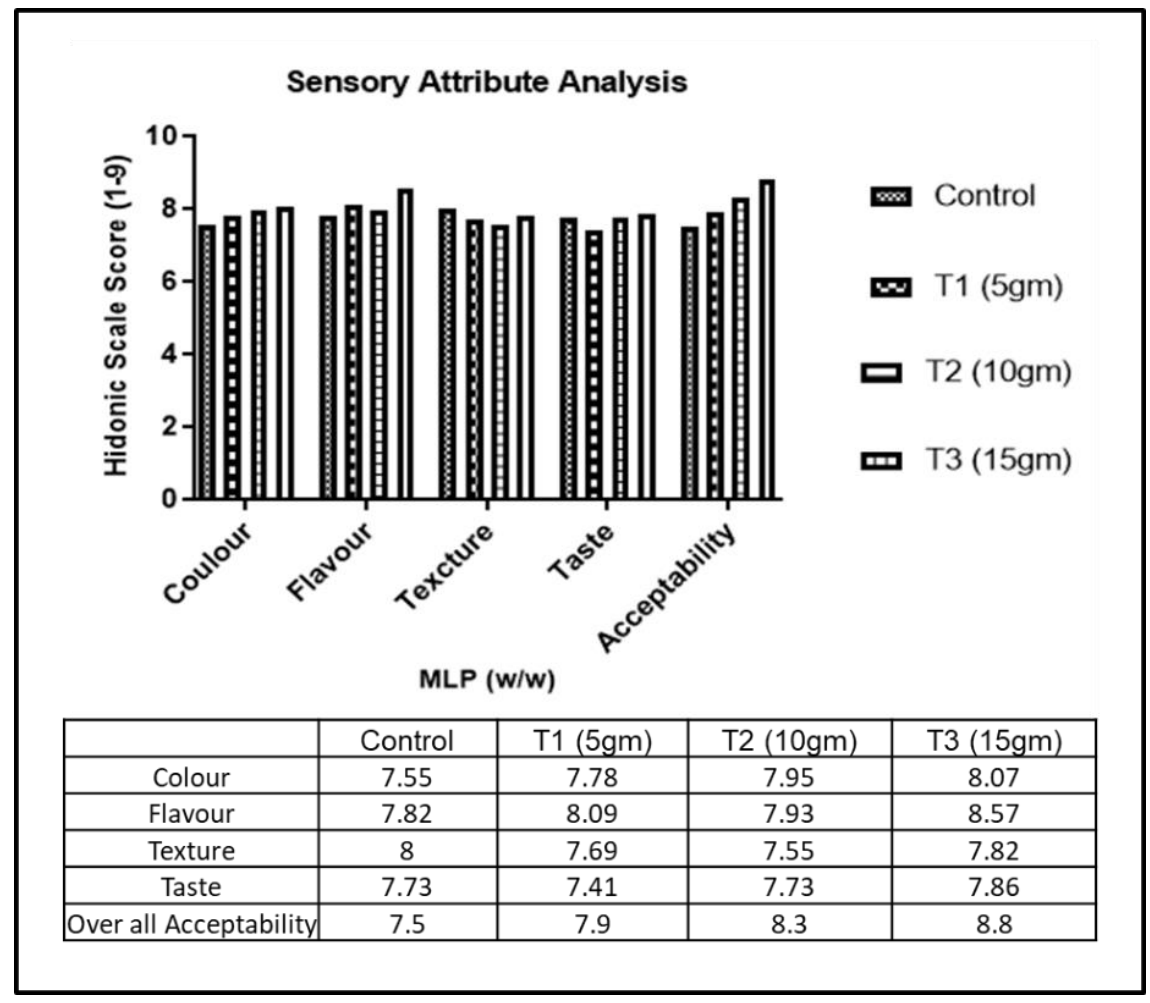

Figure. 6: Sensory Attributes analysis of Control and Pasta fortified with MLP at various concentration i.e. T1 $(5 \mathrm{gm}), \mathrm{T} 2(10 \mathrm{gm}), \mathrm{T} 3(15 \mathrm{gm})$. This analysis is performed on the basis of 9 point hedonic scale system.

The current study, indicates that the supplementation of Moringa oleifera leaf powder (MLP) with Pasta can be a better choice as it significantly improved the nutritional quality especially in micro \& macro nutrients. The results of cooking quality and sensory analysis indicated that pasta fortified with different concentrations of Moringa oleifera is well accepted by panellist and there cooking quality was not very much affected by incorporation of MLP. Also, the fortified pasta products with underutilized tree Moringa oleifera leaves powder (MLP) is a cost effective and nutritional approach with long storage capability for enhancing the nutritional value particularly for the people who are affected by malnutrition women and children from rural area as well as some urban area of the country.

\section{ACKNOWLEDGEMENT}

The authors are also grateful to the Institutes of Food Technology, Bundelkhand University, Jhansi, India., to allow this practical's work, and also all the panellists for the sensory evaluation of Pasta samples. 


\section{REFERENCES}

AACC International (2002). Approved Methods of the American Association of Cereal Chemistry, In: 11th Ed. Methods 66-50, Pasta and Noodle Cooking QualityFirmness, AACC International: Saint Paul, 2000.

Abd El-Baky, H.H., G.S. El-Baroty, (2013). The potential use of micro-algal carotenoids as dietary supplements and natural preservative ingredients, J. Aqua Food Prod. Tech. 22: 392-406.

Aluko, O., M.R. Brai, A.O. Adelore (2013). Materials evaluation of sensory attributes of snack from maize-moringa seed flour blends. Int. J. Innov. Res. Sci. Eng. Technol., 7 (597-599).

American Association of Cereal Chemists - AACC (2000). Approved methods of the AACC (10th Ed.). St. Paul.

American Association of Cereal Chemists (2008). Approved Methods of the AACC, 10th edition. AACC, St Paul.

Andersen, P. A. (1993). Livsmedelsteknologi Lund, Sverige: Student literature. Pp 39.

Antognelli, C. (1980). The manufacture of pasta as a food ingredient: A review. J. Food Tech.15: 125-145.

Bordenave, N, Hamaker, B.R., Ferruzzim M. G. (2014). Nature and consequences of noncovalent interactions between flavonoids and macronutrients in foods. Food Funct $5: 18-34$

Brennan, C.S., Kurim, V. and Tudorica, C. M. (2004). Inulin-enriched pasta: effects on textural properties and starch degradation. J Food Chem 86:189-193.

Bui, L. T. T. and Small, D. M. (2007). The contribution of Asian noodles to dietary thiamine intakes: A study of commercial dried products. J Food Compos Anal 20:575-583.

Cubadda, R. (1994). Nutritional value of pasta. Effects of processing conditions, Italian Journal of Food and Beverage Technology. 3: 27-33.

Delcour, J. A., Vansteelandt, M., Hythier, C., Abecassis, J., Sindic, M. and Deroanne, C. (2000). Fractionation and reconstitution provide insight into the role of gluten and starch interactions in pasta quality. J Agric Food Chem 48:3767-3773.

Dexter, J. E., Matsuo, R. R. (1979). Influence of protein content on some durum wheat quality parameters. Can J Plant Sci 57:717-27.edition. AACC, St Paul (2008).

Edwards, N. M., Izydorczyk, M. S., Dexter, J. E. and Biliaderis, C.G. (1993). Cooked pasta texture: comparison of dynamic viscoelastic properties to instrumental assessment of firmness. Cereal Chem 70:122-126.

FDA, (1999). Food labelling health claims: Soy protein and coronary heart disease. Federal Register 64: 57699-57733. 
Feillet, P. and J. E. Dexter (1996). Quality requirements of durum wheat for semolina milling and pasta production. In: J.E. Kruger, R.R. Matsuo and J.W. Dick, Editors, Pasta and noodle technology, American Association of Cereal Chemists, St. Paul, M.N., USA. 95-131.

Fellows, P. (1997). Properties of Foods and Processing Theory, in Food Processing Technology - Principles and Practice, ed. by Fellows PJ. Woodhead Publishing Limited and CRC Press LLC, London.

Fennema, O. R. (1996). Food Chemistry. Marcel Dekker, Inc. New York, United States of America.

Foschia, M., D. Peressini, A. Sensidoni, M. A. Brennan, and C. S. Brennan (2015). "How combinations of dietary fibres can affect physicochemical characteristics of pasta," LWT-Food Science and Technology, vol. 61, no. 1, pp. 41-46, 2015.

Gull, A., Prasad, K and Kumar, P. (2015). Optimization and functionality of millet supplemented pasta. Food Sci. Technol. Campinas 35, 625-632.

IPO, "The world pasta industry status report- 2013 International Pasta Organization," 2014, http://www.internationalpasta.org/resources/World\%20Pasta\%20Industr y\%20Survey/IPOstatreport2014low.pdf July 29, 2018.

Kakde, S. B., Masih, D. and Sonkar, C. (2018). Utilization of Moringa leaves powder as valuable food ingredients in pasta preparation .Journal of Pharmacognosy and Phytochemistry 2018; 7(4): 1053-1056

Kasolo, J.N., G.S. Bimenya, L. Ojok, J. Ochieng, J.W. Ogwal-okeng (2010). Phytochemicals and uses of Moringa oleifera leaves in Ugandan rural communities (2010), J. Med. Plants Res. 4 (2010) 753-757.

Kill, R. C. (2001a). Introduction. In: Kill RC, Turnbull K, editors. Pasta and semolina technology. Oxford: Blackwell Science Ltd. 01-10.

Lakshmipriya, G., Kruthi, D., Devarai, S. K. (2016). Moringa oleifera: A review on nutritive importance and its medicinal application, Food Science and Human Wellness. 5, 49-56.

Marconi, E. and Carcea, M. (2001). Pasta from non-traditional raw materials. Cereal Food World 46(11): 522-30.

Martinez, C. S., Ribotta, P. D, León, A. E. and Aňón, M.C. (2007). Physical, sensory and chemical evaluation of cooked spaghetti. Journal of Texture Studies. 38: 666-683.

Mishra, P., Bhatt, D. K. (2016). A Study on Development of Fortified Pasta with Ginger Powder IOSR Journal of Environmental Science, Toxicology and Food Technology. 2016; 10(8):14-18z.

Nilusha, R. A. T., J. M. J. K. Jayasinghe, O. D. A. N. Perera and P. I. P., Perera (2019). Review Article Development of Pasta Products with Nonconventional Ingredients 
and Their Effect on Selected Quality Characteristics: A Brief Overview Hindawi International Journal of Food Science Volume 2019

Owusu, I. Oduro (2011). Development of crackers from cassava and sweetpotato flours using Moringa oleifera and Ipomoea batatas leaves as fortificant Am. J. Food Nutr., 1: 114-122.

Pagani, M.A., Lucisano, M. and Mariotti, M. (2007). Traditional Italian products from wheat and other starchy flours. In Handbook of Food Products Manufacturing (Y.H. Hui, ed.) Wiley, New York, NY.

Ranganna, S. (1986). Handbook of analysis and quality control for fruits and vegetable products (chapt. 1, pp. 1-30). New Delhi: Tata McGraw-Hill.

Ronge, B.V., P.V. Padghan, R.V. Jayabhaye and R.A. Patil (2017). Studies on PhysicoChemical Properties of Vermicelli Prepared by Using Skim Milk Powder Department of Animal Science and Dairy Science, Department of Agricultural Engineering, College of Agriculture, Latur (VNMKV, Parbhani) - 413512 (M.S.), India

Savita, S., Arshwinder, K., Gurkirat K., Vikas N. (2013). International Journal of Engineering Research and Applications (IJERA). 3 (2): 1757-1763. ISSN: 22489622

Sissons, M., Ames, N., Egan, N., Rhymer, C.(2008). A comparison of two instrumental techniques used to discriminate the cooking quality of spaghetti. International Journal of Food Science and Technology. 43, 1323-1329.

Srivastava, R. P. and Kumar, S. (2009). Fruits and Vegetable drying, dehydration and concentration.3rd Edition, published by International book distributing company, Lucknow. 2009, 14.

Stephen, M. Boue, Thomas, E. Cleveland, Carol Carter-Wientjes, Betty Y. Shih, Deepak Bhatnagar, John M. McLachlan and Matthew E. Burow, (2009). PhytoalexinEnriched Functional Foods. J. Agric. Food Chem. 57 (7) 2614-2622.

Taneya, M., Biswas M. and Shams-Ud-Din, M. (2014). The studies on the preparation of instant noodles from wheat flour. Journal of Bangladesh Agriculture University 12: $135-142$.

Toepfer, E.W., M.M. Polnasky, J. F. Wart, H.T. Slover, E.R. Morris, F.N. Hepburn, and F.W. Quackenbush,(1972). Nutrient composition of selected wheats and wheat products XI Summary, Cereal Chemistry. 49: 173-186.

Tudorica, C. M., Kuri, V. and Brennan, C. S.(2002). Nutritional and physicochemical characteristics of dietary fiber enriched pasta. J Agric Food Chem 50: 347-356.

Verardo, V., Ferioli, F. and Caboni, M. F. (2009). Evaluation of lipid oxidation in spaghetti pasta enriched with long chain n-3 polyunsaturated fatty acids under different storage conditions. Food Chem. 114: 472-477. 
Sustainability, Agri, Food and Environmental Research, (ISSN: 0719-3726), 9(3), 2021; 408-424 http://dx.doi.org/10.7770/safer-V0NO-art2303

Received: $21^{\text {th }}$ August 2020; Accepted: $01^{\text {th }}$ December 2020; First distribution: $14^{\text {th }}$ January 2021. 